\title{
An Overview of Research on Optimization of Integrated Solar/Wind Power Generation Systems
}

\author{
Zhonglei Shao, Kwok Lun Lo \\ Department of Electronic and Electrical Engineering, University of Strathclyde, Glasgow, UK \\ Email: zhonglei.shao@strath.ac.uk, k.lo@strath.ac.uk
}

How to cite this paper: Shao, Z.L. and Lo, K.L. (2016) An Overview of Research on Optimization of Integrated Solar/Wind Power Generation Systems. World Journal of Engineering and Technology, 4, 35-42. http://dx.doi.org/10.4236/wjet.2016.43D005

Received: August 29, 2016

Accepted: October 13, 2016

Published: October 20, 2016

\begin{abstract}
Although transmission systems are able to cover most of the areas in many countries, there are still some isolated areas such as rural counties and remote desert lands where grid power cannot be accessed. Therefore, a reliable and economical power supply scheme is required to solve the problem. One of them combines wind/solar power generation with the support of storage system. This paper is to give an overview of the optimization methodologies about the wind/solar stand-alone system supported by storage systems or integrating with other renewable or conventional power generation sources. It is shown that continued research and optimization methodology in this area are still in great need for performance improvement.
\end{abstract}

\section{Keywords}

Solar/Wind Generation System, Optimization, Techno-Economic

\section{Introduction}

As the global environmental pollution becomes more and more serious, distributed power generation system based on renewable energy, such as photovoltaic and wind power generation, attracts more public attention. On one hand, due to the unstable and intermittent characteristic nature of wind and solar energy, a large capacity of energy storage is needed when the hybrid wind/solar power system (HWSPS) works in stand-alone model. On the other hand, a strong impact on the utility grid will occur when HWSPS works in grid-connected mode.

For consumers in some rural areas it may be difficult for them to access the conventional transmission system and the reason could be technological or economic issues, HWSPS would be a good alternative because of the complementary characteristics of wind and solar energy [1]. This paper will make a general review on researches that have been done on the HWSPS and also suggestion for future work. 


\section{Structure of the HWSPS}

Figure 1 is a general block diagram about this HWSPS. Wind turbines and Photovoltaic (PV) modules function as power suppliers. AC load or DC load are included in this system connected with inverters and rectifiers. Controller collection system keeps up good performance of whole system operation by collecting data from the other parts. Data are collected from the controller part for observation to improve the performance. Either battery banks or diesel generators are added into the system in the event of insufficient power generation from the wind and solar. Excess power generated can be stored in the battery in most conditions until the battery reaches to its maximum level. Then the overproduced power must be transmitted to the dump load to be consumed for safety.

\section{Output Power from the Wind Turbine}

Wind energy has been in use for a long time since it is clean and renewable. As a result, a way of recording wind speed accurately is highly relevant with the output power of wind turbine. It is not uncommon that the hourly records of wind speed are not available for a particular site. There are two general solutions to this problem. The first solution is to generate hourly wind speed synthetically from the monthlyaverage values of the wind speed data [1]. Another solution is to generate the wind speed data from a nearby site by making necessary adjustments [2].

The hour-by-hour simulation programs have been the main tools used to judge the long-term performance of wind energy systems. Borowy and Salameh gave a fundamental wind turbine model in [3] [4], which was further studied by other researchers [5]. The details are shown below.

Step 1: collect the wind speed data at a particular height. Most of the wind speed data are usually recorded near the ground level. These data can then be updated to the particular hub height according to formulation mentioned in [4].

Step 2: choose a proper wind speed distribution. Weibull distribution is proved to fit

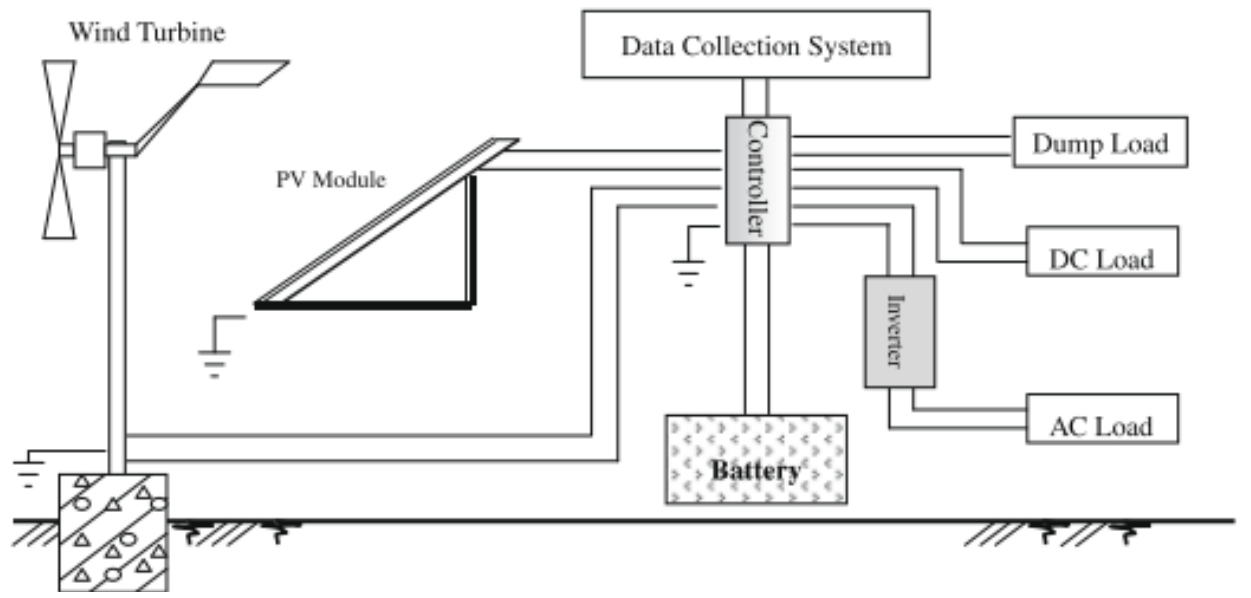

Figure 1. Block diagram of a hybrid solar-wind power generation system [5]. 
well with wind speed distribution. The wind speed distribution functions are calculated for each hour of a typical day in every month over a few years.

Step 3: calculate the instantaneous output power from the wind turbine. The instantaneous output power of the wind turbine is a function of the wind velocity, shown in

\section{Figure 2.}

Step 4: calculate the average power output of the wind turbine. Combined with the wind turbines specification provided by the manufacturer and the distribution density calculated in step 2, the average power output from the wind turbine for every hour of a typical day can be easily calculated by the following expression:

$$
P_{w . a v g}=\int_{0}^{\infty} P_{w} \cdot f(v) \cdot d v
$$

$\mathrm{f}(\mathrm{v})$ - the probability density function.

$\mathrm{P}_{\mathrm{w}}$ - the instantaneous electrical power output of a specific wind turbine.

However, sometimes the hour-by-hour wind speed data are not available for some particular sites. As a result, alternative simulation programs were developed in [6] [7] to determine the long-term performance of renewable energy systems. Themore simple the simulation model is, the less accurate it would be.

\section{Output Power from the PV Module}

Modeling of a photo voltaic system is similar tothe wind energy system [3] [4]. Details are shown below.

Step 1: Choosea PV module tilt angle. PV modules in different locations would be adjustedto different tilt angles for the purpose of the maximum use of solar irradiance. And there are some other PV modules that can track the height of the sun and adjust the tilt angle automatically.

Step 2: Collect hourly solar irradiation data and ambient temperature. Ambient temperature data are necessary because the I-V characteristic of PV module differs with the change in either temperatures or irradiations, shown in Figure 3. When the in solation level stays the same, a PV module output power would be different due to different temperature levels. A maximum power point tracker (MPPT) is used to help the PV array to output the maximum power at any radiation level [8] [9].

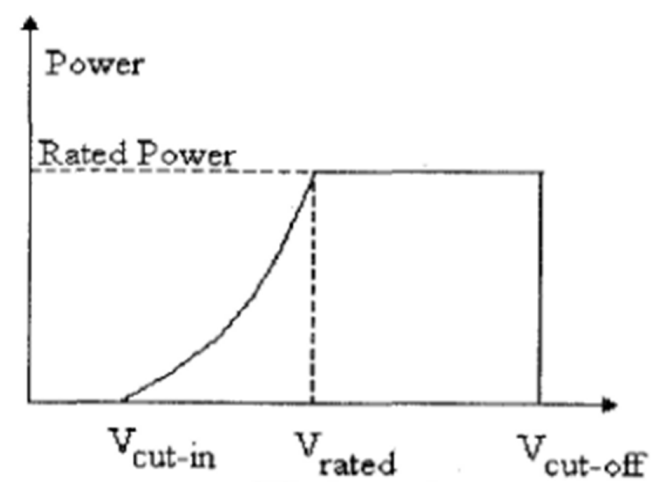

Figure 2. Power-wind speed characteristic. 


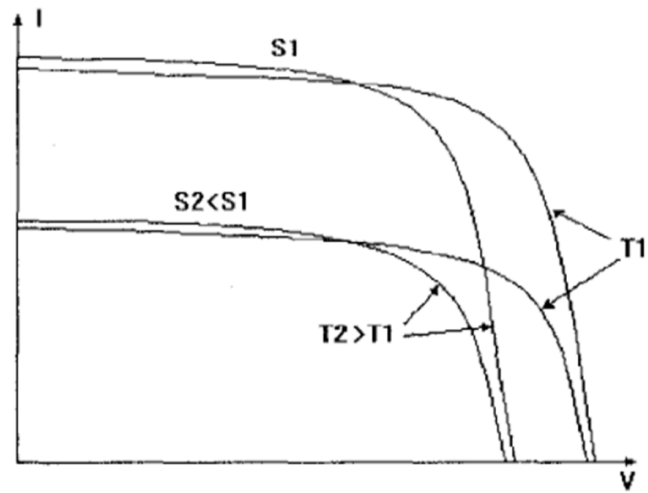

Figure 3. I-V Characteristics of a solar module for different insolation levels S1 and S2 with two different ambient temperatures T1 and T2 [4].

Step 3: Choose a proper solar irradiance distribution. Because of some insolation reducing phenomena such as different cloud cover, the solar irradiance is also a random variable which can be represented by a particular density function. Like Weibull density function is often used to estimate wind speed, Beta density function is usually chosen to describe the solar irradiance distribution [4] [5].

Step 4: Calculate the average power output from the PV module.Combined with the $\mathrm{PV}$ array specification provided by the manufacturerand the distribution density calculated in step 3, the average power output from the PV module for every hour of a typical day can be easily calculated by following expression [3]:

$$
P_{p v, a v g}=\int P(S) \cdot f(S) \cdot d S
$$

$\mathrm{f}(\mathrm{S})$-irradiance probability density function

$\mathrm{P}(\mathrm{S})$ - the electrical power output of a particular PV array

Another novel model based on the I-V curves of a PV module was proposed in [10] to predict the PV module performance for engineering applications with limited data provided by the PV module manufacturers. Five parameters are introduced to account for the complex dependence of the PV module performance upon the solar-irradiance intensity and PV module temperature. It is claimed that this model is exceptionallysimple and useful to calculate the actual performances of the PV modules under operating conditions.

\section{Modeling of Battery Storage System}

Battery storage system is necessary for HWSPS. On one hand, it contributes a lot to the reliability of the whole system. On the other hand, it reduces the amount of dump load when more power than demand is produced.

Two common conditions are accepted by most of the researchers used to analyze the operation performance of the battery. One situation is that when power generated by both the PV arrays and the wind turbines exceeds the load, the battery will enter a charging condition. The other is that when the power generated by both the PV arrays and the wind turbines is insufficient to supply the load, the battery will enter a dis- 
charging condition.

State of charge (SOC) is an important parameter that tells the current operating condition of the battery. To help to prolong battery life spans, a limited range of depth of discharge (DOD) is set which means a limited maximum power can be withdrawn from the battery. According to the specifications from the manufacturers, the battery's lifetime can be prolonged to its maximum if DOD takes the value of $30 \%-50 \%$ [11]. And it is obvious that battery cannot hold any more amount of power when its capacity is reached. Then the surplus power must be transmitted to the dump load [5].

It was mentioned in [11] that only when the output voltage of PV array was higher than the float charge voltage of battery bank could the electric energy generated by PV array be used. Ref [11] introduced a way of judging whether the output of PV array was available by using a formula relating the terminal voltage of battery bank with charge quantity and ambient temperature. In practice, the way of connection of PV modules should meet the demand requirement of users both on voltage and power. The operating voltage is determined by the number of the PV array connected in series, whereas in parallel the number of battery bank strings determines the capacity of the PV array.

Umarin Sangpanich gave assumption in [12] that the less amount of energy discharged each time from a battery, the less damaging the battery storage systems would be. This process can lead to more comprehensive battery discharging process considering discharge duration by setting a range of the permitted discharging power. As a result, a different optimization algorithm of the battery management assumption considering the dynamic nature of the energy storage is posed which can lead to more future work on the battery storage system.

\section{Diesel Generator Support}

Diesel generators sometimes are also added into the HWSPS as support to improve the system reliability. It is largely due to diesel generators can provide a more stable power supply when insufficient power are produced from the wind turbine and PV array modules and the storage is depleted. One big disadvantage of diesel generators is its relatively high $\mathrm{CO} 2$ emission which would lead to damage to the environment.

A methodology to size an optimal stand-alone hybrid PV/wind/diesel/battery bank using a Multi-Objective Genetic Algorithm was developed in [13]. The diesel generator model is designed for operating between $30 \%$ and $100 \%$ of their nominal power to keep a healthy lifetime. Three different kinds of diesel generators with varied nominal output power and costwere applied in [13]. With data of solar radiation, temperature and wind speed collected from Gandon, the north-western of Senegal, obtained results are presented as optimal Pareto front. Each solution from the methodology included three indices i.e. the optimal number of devices, the levelized cost of energy (LCE) and the amount of $\mathrm{CO}_{2}$ emission. he results showed that the amount of the $\mathrm{CO}_{2}$ emission decreased as the value of LCE increased. On one hand, local government would put money on emissions treatment. On the other hand, increased number of diesel generators means fewer numbers of PV modules, wind turbines and especially the batteries 
which are usually the most expensive parts, leading to less LCE.It is concluded that the use of the diesel generatorscan make an influence on the optimization of configuration. If a proper type of diesel generator is chosen then the total cost of the system would be minimized.

\section{Reliability Issues in Stand-Alone and Grid-Connected Models}

Stand-alone HWSPS is an isolated system which only supports devices inside the system. The definition of Loss of Power Supply Probability (LPSP) is popular among researchers and has become a standard parameter used to represent the reliability of the aimed stand-alone system. LPSP is defined as the probability that an insufficient power supply results when the combined hybrid system (PV array, wind turbine, and battery) is unable to satisfy the load demand [15]. In other words, a zero value of LPSP means the load will always be satisfied and a unity value of LPSP means that the load will never be satisfied [4].

An improved optimal sizing method considering the system in both stand-alone and grid-connected operation conditions was proposed in [14]. Some objectives such as high power supply reliability, full utilization of the complementary characteristics of the wind and solar, small fluctuation of power injected into the grid and minimization of the total cost of the system are set and realized. It is shown that when the HWSPS is in a grid-connected mode, the power injected into the grid would have an impact on power quality of the utility grid. An energy filter is further applied to help smooth the fluctuation of injected power. The standard deviation (STD) and power fluctuation rate are two important parameters when considering the fluctuation of injected power. The STD is the result related with the instantaneous and average power injected into the grid during certainperiod. The power fluctuation rate is relatedto the maximum and minimum power injected into the grid during certain time interval. It is obvious that the smaller STD and power fluctuation rate, the smaller is the power fluctuation.

\section{Economic Issues}

No investors will put money into a system that is not cost-effective even when a zero LPSP condition can be achieved. As a result, from the point of an investor, not only the achieved optimum configuration should meet the power reliability requirement but also the whole system is worthwhile to be invested in [16]. The concept of life cycle cost of the system has been accepted by most researchers. This concept consists of the initial capital cost, the operation and maintenance cost and the components replacement cost. The initial capital cost is mainly from prices of PV arrays, wind turbines and batteries. The present worth value can be calculated by using the capital recovery factor which is related to the actual interest rate. Operation and maintenance cost are usually counted as a percentage part of the initial capital cost for simplicity. The replacement cost is usually included when the project lifetime (usually 15 to 20 years) exceeds the lifetime of the distributed generators [17].

When diesel generators are included in the system, $\mathrm{CO}_{2}$ emission effect should also 
be accounted. It is obvious that the government's subsidy or credit also plays an important part when analyzing the economy of a renewable energy system which would lead the results to be more accurate and reasonable. What is more, a loss of power supply or a strongly fluctuant power should also be accounted when it is a grid-connected HSWPS model. It is due to the reason that fluctuant power would increase the regulation cost of the utility grid. As a result, a penalty cost is considered when the power supply reliability or the fluctuation of power injected into the grid cannot meet the requirements [14].

\section{Conclusions}

This paper has presented a general review to achieve an optimized wind/solar hybrid system. Different models have been presented in some details including wind part, solar part and battery storage, diesel support. Important parameters are the wind turbine height and PV module tilt angle.

It is noted that not only the reliability level but also investment cost should be counted. Both stand-alone and grid-connected models have been mentioned. When it is a grid-connected condition, the fluctuation should be considered because it can increase the investment cost and has an effect on system reliability.

Further work is still needed especially in finding a new optimization algorithm for the battery management considering the dynamic nature of the energy storage.

\section{References}

[1] Knight, K.M., Klein, S.A. and Duffie, J.A. (1991) A Methodology for the Synthesis of Hourly Weather Data. Solar Energy. http://dx.doi.org/10.1016/0038-092X(91)90023-P

[2] Wahab, M.A. and Essa, K.S.M. (1998) Extrapolation of Solar Irradiation Measurements: Case Study over Egypt. Renew Energy.

[3] Borowy, B.S. and Salameh, Z.M. (1994) Optimum Photovoltaic Array Size for a Hybrid Wind/PV System. IEEE Trans. on Energy Conversion, 9, 482-488. http://dx.doi.org/10.1109/60.326466

[4] Borowy, B.S. and Salameh, Z.M. (1996) Methodology for Optimally Sizing the Combination of a Battery Bank and PV Array in a Wind/PV Hybrid System. IEEE Trans. On Energy Conversion, 11, 367-375. http://dx.doi.org/10.1109/60.507648

[5] Zhou, W., Lou, C.Z., Li, Z.S., Lu, L. and Yang, H.X. (2010) Current Status of Research on Optimum Sizing of Stand-Alone Hybrid Solar-Wind Power Generation Systems. Applied Energy, 87, 380-389. http://dx.doi.org/10.1016/j.apenergy.2009.08.012

[6] Siegel, M.D., Klein, S.A. and Beckman, W.A. (1981) A Simplified Method for Estimating the Yearly-Mean Performance of PV Systems. Solar Energy. http://dx.doi.org/10.1016/0038-092X(81)90220-6

[7] Clark, D.R., Klein, S.A. and Beckman, W.A. (1984) A Method for Estimating the Performance of PV Systems. Solar Energy. http://dx.doi.org/10.1016/0038-092X(84)90010-0

[8] Kratochvil, J.A., Boyson, W.E. and King, D.L. (2004) Photovoltaic Array Performance Model; Technical Report; Sandia National Laboratories: New Mexico. http://dx.doi.org/10.2172/919131

[9] Soto, W.D., Klein, S. and Beckman, W. (2006) Improvement and Validation of a Model for 
Photovoltaic Array Performance. Sol. Energy, 80, 78-88.

http://dx.doi.org/10.1016/j.solener.2005.06.010

[10] Zhou, W., Yang, H.X. and Fang, Z.H. (2007) A Novel Model for Photovoltaic Array Performance Prediction. Applied Energy, 84, 1187-1198.

http://dx.doi.org/10.1016/j.apenergy.2007.04.006

[11] Ai, B., Yang, H., Shen, H. and Liao, X. (2003) Computer-Aided Design of PV/Wind Hybrid System. Renewable Energy, 28, 1491-1512.

http://dx.doi.org/10.1016/S0960-1481(03)00011-9

[12] Umarin,S. (2012) Optimization of Wind-Solar Energy Systems Using Low Wind Speed Turbines to Improve Rural Electrification, A Thesis for the Degree of Doctor of Philosophy at the University of Strathclyde.

[13] Bilal, B.O., Sambou, V., Kébé, C.M.F., Ndiaye, P.A. and Ndongo, M. (2012) Methodology to Size an Optimal Stand-Alone PV/Wind/Diesel/Battery System Minimizing the Levelized Cost of Energy and the $\mathrm{CO}_{2}$ Emissions. Energy Procedia, 14, 1636-1647. http://dx.doi.org/10.1016/j.egypro.2011.12.1145

[14] Xu, L., Ruan, X.B., Mao, C.X., Zhang, B.H. and Luo, Y. (2013) An Improved Optimal Sizing Method for Wind-Solar-Battery Hybrid Power System. IEEE Trans. Sustain. Energy, 4, 774785 .

[15] Kaabeche, A., Belhamel, M. and Ibtiouen, R. (2010) Optimal Sizing Method for StandAlone Hybrid PV-Wind Power Generation System.

[16] Prasad, A. and Natarajan, E. (2006) Optimization of Integrated Photovoltaic-Wind Power Generation Systems with Battery Storage. Energy, 31, 1943-1954.

http://dx.doi.org/10.1016/j.energy.2005.10.032

[17] Koutroulis, E., Kolokotsa, D., Potirakis, A. and Kalaitzakis, K. (2006) Methodology for Optimal Sizing of Stand-Alone Photovoltaic/Wind-Generator Systems Using Genetic Algorithms. Solar Energy, 80, 1072-1088. http://dx.doi.org/10.1016/j.solener.2005.11.002

Submit or recommend next manuscript to SCIRP and we will provide best service for you:

Accepting pre-submission inquiries through Email, Facebook, LinkedIn, Twitter, etc. A wide selection of journals (inclusive of 9 subjects, more than 200 journals)

Providing 24-hour high-quality service

User-friendly online submission system

Fair and swift peer-review system

Efficient typesetting and proofreading procedure

Display of the result of downloads and visits, as well as the number of cited articles Maximum dissemination of your research work

Submit your manuscript at: http://papersubmission.scirp.org/

Or contactwjet@scirp.org 